\title{
The Response of DC Shunt Motor during Starting
}

\author{
ALhbeeb Babaker ALhbeeb Babaker \\ Sinnar University, Faculty of Engineering, Dep. of Electrical Engineering, Sudan
}

\begin{abstract}
In this study, it has been shown that it is possible to reduce the armature current during starting. Thus minimizes the risks that lead to collapse of the machine. In addition, much interest in this research has been conducted to discuss dynamic performance of DC shunt motor during starting by analysis the mathematical equation of DC shunt motor and derivation them to find the final modal. Then MATLAB PROGRAM is used to during starting and shows the results in the scope.
\end{abstract}

\section{1- INTRODUCTION}

The shunt motor is widely used and therefore it is an appropriate candidate to illustrate the dynamic performance of a typical dc machine. This hunt motor has a large number of turns of fine wire in comparison. Further ,the field winding is connected across the armature-that is to say, in parallel with it. [1]

In starting up a motor off constant voltage supply mains resistance is there for included in the armature circuit. The value of this resistance is arranged so that on closing the circuit the required current is sufficient to develop the necessary starting torque; As the motor speeds up, back emf; is generated and the current falls and with it the value of the torque developed by the armature. If the resistance were left in circuit stable conditions of speed would soon obtain when the current had fallen to a value such that the torque developed merely sufficed to overcome motor friction and to provide the load torque and no further torque was available for acceleration with the large resistance necessary to limit the current at starting, this steady speed would be very low and in addition there would be considerable waste of power in the resistance it therefore becomes necessary to cut out the whole of the starting resistance, step by step , until " free running "'is obtained and the motor is connected directly across the supply system and all external resistance cut out. [3]

\section{SHUNT DC MOTOR}

In the shunt motor the field winding is connected in parallel or in shunt with the armature winding. (See figure 2.15) The resistance in the field winding is high. Since the field winding is connected directly across the power supply, the current through the field is constant. The field current does not vary with motor speed, as in the series motor and, therefore, the torque of the shunt motor will vary only with the current through the armature. The torque developed at starting is less than that developed by a series motor of equal size.

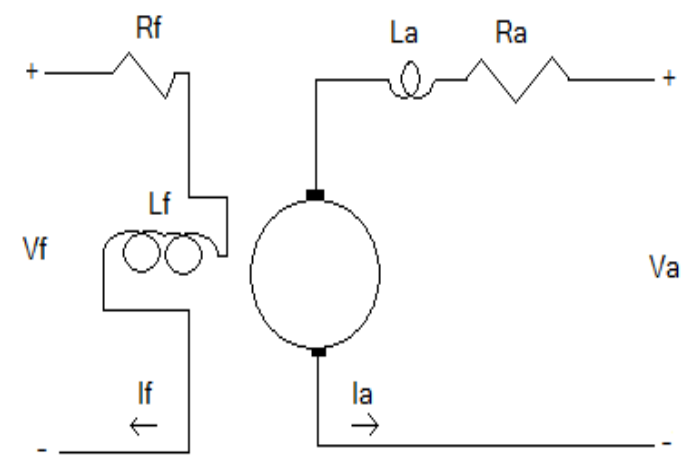

Where:

Fig (2.1): Shunt motor

$V_{f}=$ Field voltage

$V_{a}=$ Armature vtolage

$I_{f}=$ Field current

$I_{a}=$ Armature current 
$R_{f}=$ Field Resistance

$R_{a}=$ Armature Resistance

$L_{f}=$ Field Inductance

$L_{a}=$ Armature Inductance

The speed of the shunt motor varies very little with changes in load. When all loads are removed, it assumes a speed slightly higher than the loaded speed. This motor is particularly suitable for use when constant speed is desired and when high starting torque is not needed.

\section{DC MOTOR STARTERS}

The counter- emf aids the armature resistance to limit the current through the armature. When power is first applied to a motor, the armature does not rotate. At that instant the counter- emf is zero and the only factor limiting the armature current is the armature resistance. Usually the armature resistance of a motor is less than $1 \Omega$; therefore the current through the armature would be very large when the power is applied. This current can make an excessive voltage drop affecting other equipment in the circuit and even trip overload protective devices. Therefore the need arises for an additional resistance in series with the armature to limit the current until the motor rotation can build up the counter- emf. As the motor rotation builds up, the resistance is gradually cut out.

\subsection{Manual- Starting Rheostat}

When electrical and DC motor technology was first developed, much of the equipment was constantly tended by an operator trained in the management of motor systems. The very first motor management systems were almost completely manual, with an attendant starting and stopping the motors, cleaning the equipment, repairing any mechanical failures, and so forth. The first DC motor-starters were also completely manual, as shown in this image. Normally it took the operator about ten seconds to slowly advance the rheostat across the contacts to gradually increase input power up to operating speed. There were two different classes of these rheostats, one used for starting only, and one for starting and speed regulation. The starting rheostat was less expensive, but had smaller resistance elements that would burn out if required to run a motor at a constant reduced speed. This starter includes a no-voltage magnetic holding feature, which causes the rheostat to spring to the off position if power is lost, so that the motor does not later attempt to restart in the full-voltage position. It also has over current protection that trips the lever to the off position if excessive current over a set amount is detected.

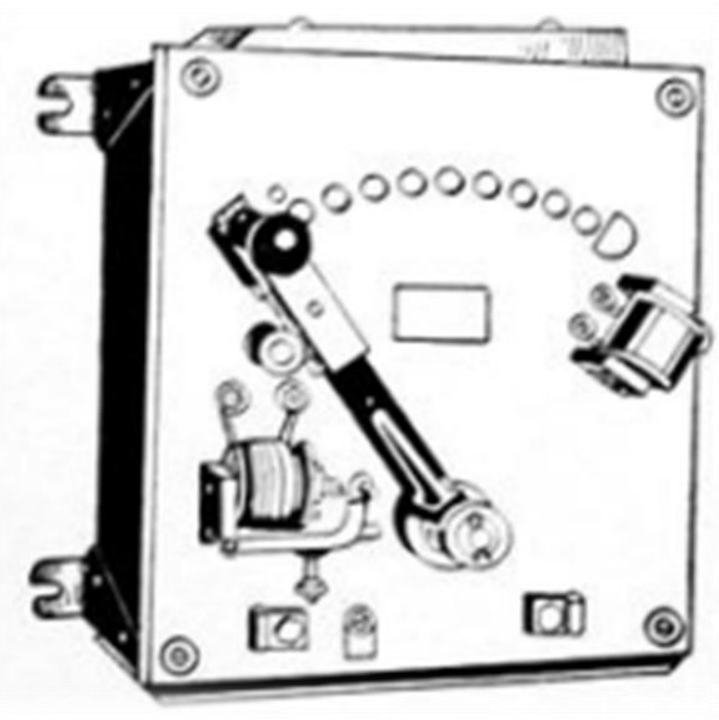

Fig (2.17): DC motor manual starting rheostat with no Voltage

\subsection{Three- point starter}

he incoming power is indicated as L1 and L2. The components within the broken lines form the three-point starter. As the name implies there are only three connections to the starter. The connections to the armature are indicated as A1 and A2. The ends of the field (excitement) coil are indicated as F1 and F2. In order to control the speed, a field rheostat is connected in series with the shunt field. One side of the line is connected to the arm of the starter (represented by an arrow in the diagram). The arm is spring-loaded so, it will return to the "Off" position when not held at any other position. On the first step of the arm, full line voltage is applied across the shunt field. Since the field rheostat is normally 
International Journal of Innovative Research in

Electrical, Electronics, Instrumentation and Control Engineering

Vol. 9, Issue 1, January 2021

DOI 10.17148/IJIREEICE.2021.9106

set to minimum resistance, the speed of the motor will not be excessive; additionally, the motor will develop a large starting torque. The starter also connects an electromagnet in series with the shunt field. It will hold the arm in position when the arm makes contact with the magnet. Meanwhile that voltage is applied to the shunt field, and the starting resistance limits the current to the armature. As the motor picks up speed counter-emf is built up; the arm is moved slowly to short.

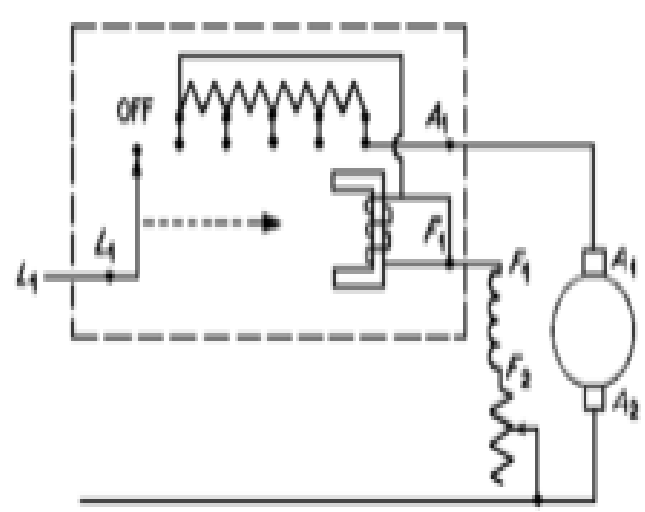

Fig (2.18) Four- point starter

The four-point starter eliminates the drawback of the three-point starter. In addition to the same three points that were in use with the three-point starter, the other side of the line, L1, is the fourth point brought to the starter when the arm is moved from the "Off" position. The coil of the holding magnet is connected across the line. The holding magnet and starting resistors function identical as in the three-point starter. The possibility of accidentally opening the field circuit is quite remote. The four-point starter provides the no-voltage protection to the motor. If the power fails, the motor is disconnected from the line.

\section{MATHEMATICAL MODEL}

In Figure (2.1)The transformation matrix between voltage $\&$ current is:

The equations are:

$$
\left[\begin{array}{l}
V_{a} \\
V_{f}
\end{array}\right]=\left[\begin{array}{cc}
R a+L a P & -\omega M \\
0 & R f+L f P
\end{array}\right]\left[\begin{array}{l}
I_{a} \\
I_{f}
\end{array}\right]
$$

$V_{a}=R_{a} I_{a}+L_{a} \mathrm{P} I_{a}-\omega \mathrm{MI} I_{f}$

$V_{f}=R_{f} I_{f}+L_{f} \mathrm{P} I_{f}$

We can write the above equations in form:

$[\mathrm{V}]=[\mathrm{RI}]+[\mathrm{L}][\mathrm{PI}]+\omega[\mathrm{G}][\mathrm{I}]$

By putting PI in the left hand of equation

$[\mathrm{P} \mathrm{I}]=[L]^{-1}[[\mathrm{~V}]-[\mathrm{R} \mathrm{I}]-\omega[\mathrm{G}][\mathrm{I}]]$

BY rewrite equation (4)

After calculation:

$$
\left[\begin{array}{l}
P I_{a} \\
P I_{f}
\end{array}\right]=\left[\begin{array}{cc}
L_{a} & 0 \\
0 & L_{f}
\end{array}\right]^{-1}\left[\begin{array}{c}
V_{a} \\
V_{f}
\end{array}\right]-\left[\begin{array}{c}
R_{a} I_{a} \\
R_{f} I_{f}
\end{array}\right]-\omega\left[\begin{array}{cc}
0 & -M \\
0 & 0
\end{array}\right]\left[\begin{array}{c}
I_{a} \\
I_{f}
\end{array}\right]
$$

Therefore, the final equations are:

$$
\left[\begin{array}{c}
P I_{a} \\
P I_{f}
\end{array}\right]=\left[\begin{array}{c}
1 / L_{a} \\
1 / L_{f}
\end{array}\right]\left[\begin{array}{c}
V_{a}-R_{a} I_{a}+\omega M I_{f} \\
V_{f}-R_{f}
\end{array}\right]
$$

$\mathrm{PI} I_{a}=\left(V_{a}-R_{a} I_{a}+\omega \mathrm{M} I_{f}\right) / L_{a} \ldots$ (4.5)

$\mathrm{P} I_{a}=\left(V_{f}-R_{f} I_{f}\right) / L_{f}$

\section{THE TORQUE EQUATION IS:}

$\mathrm{Te}=\left[I_{T}\right][\mathrm{G}][I]$

$$
\left[T_{e}\right]=\left[\begin{array}{ll}
I_{a} & I_{f}
\end{array}\right]\left[\begin{array}{cc}
0 & -M \\
0 & 0
\end{array}\right]\left[\begin{array}{c}
I_{a} \\
I_{f}
\end{array}\right]
$$


By determine the torque equation we find:

$\mathrm{Te}=-\mathrm{M} I_{a}$

\section{STARTER DESIGN:-}

Now we use the starter shown in figure below:

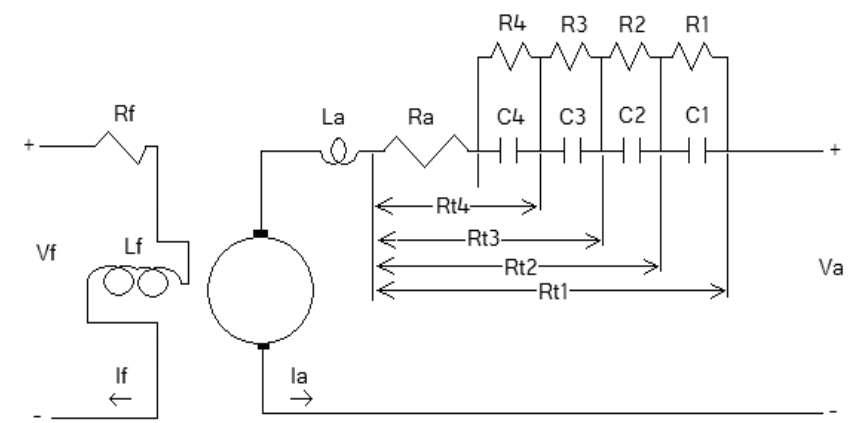

Figure (3) Equivalent circuit of a dc motor with external resistance

From fig (3.5) we can write down all the equation of dc motor with the starter, the question is:

How many steps are required to accomplish the current limiting? To find out, define $\mathrm{R}_{\text {total }}$ as the original resistance in the starting circuit. So $\mathrm{R}_{\text {total }}$ is the sum of the resistance of each stage of the starting resistor together with the resistance of the armature circuit of the motor:

$$
\mathrm{R}_{\text {total }}=\mathrm{R}_{1}+\mathrm{R}_{2}+\cdots+\mathrm{R}_{\mathrm{a}}
$$

Now define $R_{\text {total } i}$ as the total resistance left in the starting circuit after stages 1 to $i$ have been shorted out. The resistance left in the circuit after removing stages 1 through $\mathrm{i}$ is:

$\mathrm{R}_{\text {total } \mathrm{i}}=\mathrm{R}_{\mathrm{i}+1}+\cdots+\mathrm{R}_{\mathrm{a}}$

Note also that the initial starting resistance must be

$\mathrm{R}_{\text {total }}=\frac{\mathrm{V}_{\mathrm{t}}}{\mathrm{I}_{\max }}$

In the first stage of the starter circuit, resistance $R_{1}$ must be switched out of the circuit when the current $I_{A}$ falls to:

$\mathrm{I}_{\mathrm{a}}=\frac{\mathrm{V}_{\mathrm{t}}-\mathrm{E}_{\mathrm{a}}}{\mathrm{R}_{\text {total }}}=\mathrm{I}_{\min }$

After switching that part of the resistance out, the armature current must jump to:

$\mathrm{I}_{\mathrm{a}}=\frac{\mathrm{V}_{\mathrm{t}}-\mathrm{E}_{\mathrm{a}}}{\mathrm{R}_{\text {totali }}}=\mathrm{I}_{\max }$

Since $\left(E_{a}=k \emptyset w\right)$ is directly proportional to the speed of the motor, which can-not change instantaneously, the quantity $V_{t}-E_{a}$ must be constant at the instant the resistance is switched out. Therefore,

$I_{\text {min }} R_{\text {total }}=V_{t}-E_{a}=I_{\text {max }} R_{\text {totali }}$

$\mathrm{R}_{\text {totali }}=\frac{\mathrm{I}_{\min }}{\mathrm{I}_{\max }} \mathrm{R}_{\text {total }}$

By direct extension, the resistance left in the circuit after the nth stage is switched out is:

$\mathrm{R}_{\text {totaln }}=\left(\frac{\mathrm{I}_{\min }}{\mathrm{I}_{\max }}\right)^{\mathrm{n}} \mathrm{R}_{\text {total }}$

The starting process is completed when $\mathrm{R}_{\text {total } \mathrm{n}}$ for stage $\mathrm{n}$ is less than or equal to the internal armature resistance $\mathrm{R}_{\mathrm{a}}$, of the motor. At that point, RA can limit the current to the desired value all by itself.

At the boundary where $R_{a}=R_{\text {total } n}$.

$\frac{\mathrm{R}_{\mathrm{a}}}{\mathrm{R}_{\text {total }}}=\left(\frac{\mathrm{I}_{\min }}{\mathrm{I}_{\max }}\right)^{\mathrm{n}}$

$$
\mathrm{R}_{\mathrm{a}}=\mathrm{R}_{\text {totaln }}=\left(\frac{\mathrm{I}_{\min }}{\mathrm{I}_{\max }}\right)^{\mathrm{n}} \mathrm{R}_{\text {total }}
$$

Solving for $\mathrm{n}$ yields:

$$
\mathrm{n}=\frac{\log \left(\mathrm{R}_{\mathrm{a}} / \mathrm{R}_{\text {total }}\right)}{\log \left(\mathrm{I}_{\min } / \mathrm{I}_{\max }\right)}
$$

Where $\mathrm{n}$ must be rounded up to the next integer value, since it is not possible to have a fractional number of starting stages. If $\mathrm{n}$ has a fractional part, then when the final stage of starting resistance is removed, the armature current of the motor will jump up to a value smaller than $\mathrm{I}_{\max }$. 
International Journal of Innovative Research in

Electrical, Electronics, Instrumentation and Control Engineering

Vol. 9, Issue 1, January 2021

\section{DOI 10.17148/IJIREEICE.2021.9106}

\section{5- SIMULATION RESULTS:-}

The data of the used for dc shunt motor:

(Case study) is presented in table (1) below.

When the parameters in table (1) are substituted in equations (5.2) to (5.9) the number steps (N) and starting resistances of the dc shunt motor is found as follows:

$\mathrm{N}=3$

$\mathrm{R}_{1}=3.7 \quad \mathrm{R}_{2}=1.85 \quad \mathrm{R}_{3}=0.995$

Table (1) the parameters for dc shunt motor:

\begin{tabular}{|l}
$R_{f}=240 \Omega$ \\
$R_{a}=0.6 \Omega$ \\
$\mathrm{La}=0.012 \mathrm{H}$ \\
$L_{f}=120 \mathrm{H}$ \\
$V_{a}=240 \mathrm{~V}$ \\
$V_{f}=240 \mathrm{~V}$ \\
$\mathrm{I}_{\text {Rated }}=16.2 \mathrm{~A}$ \\
Speed of motor is 1220 r.p.m. \\
\hline
\end{tabular}

The figures below illustrate the response of DC shunt motor during starting when the starter is used for threestep of resistance to reduce the starting current $(\mathrm{N}=3)$.

\section{Characteristic of motor without starter}

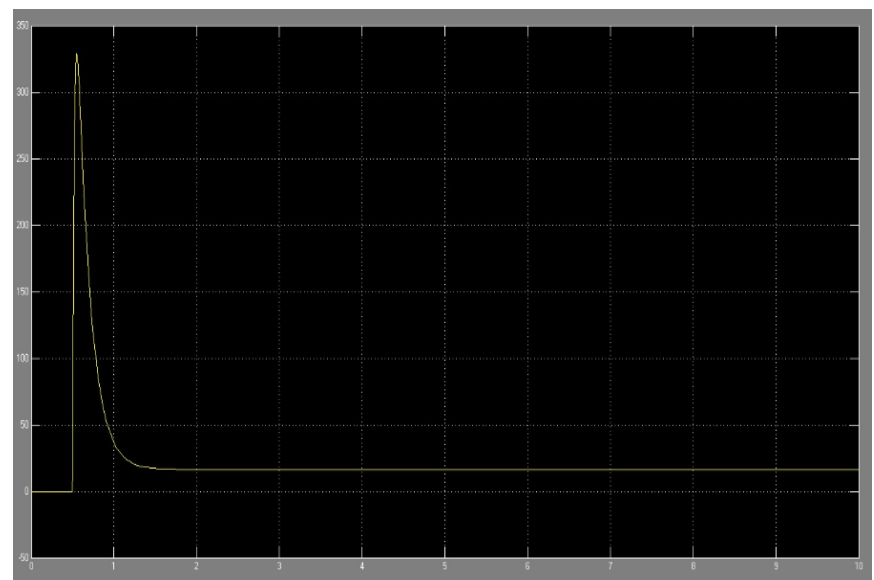

Fig (5.1): armature Current Characteristic

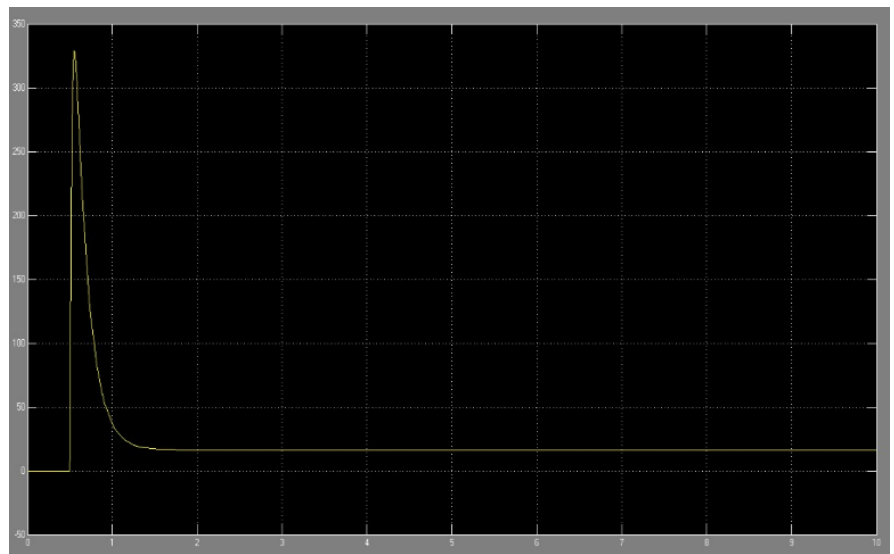

Fig (5.2): electrical torque Characteristic 
International Journal of Innovative Research in

Electrical, Electronics, Instrumentation and Control Engineering

Vol. 9, Issue 1, January 2021

DOI 10.17148/IJIREEICE.2021.9106

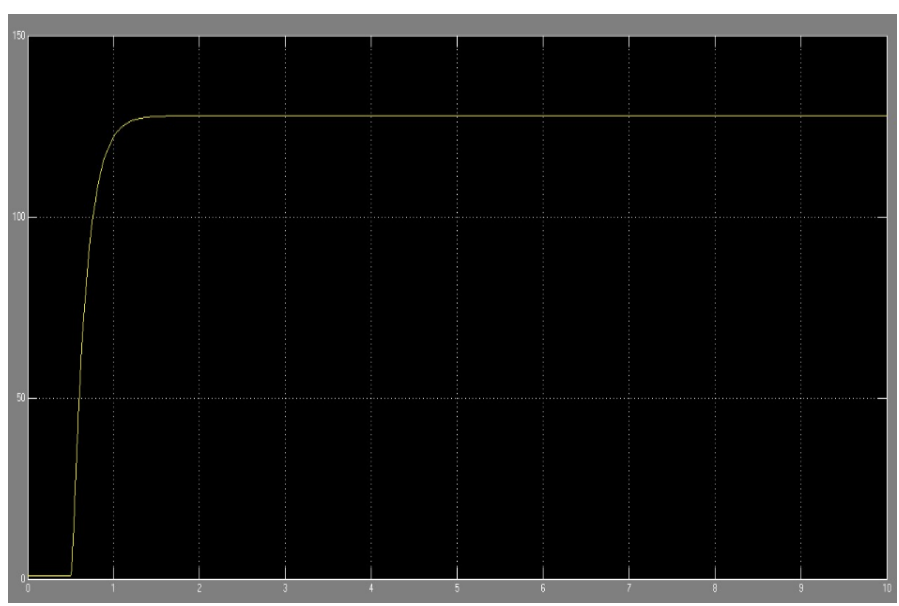

Fig (5.3): speed Characteristic

\section{Characteristic of motor with starter}

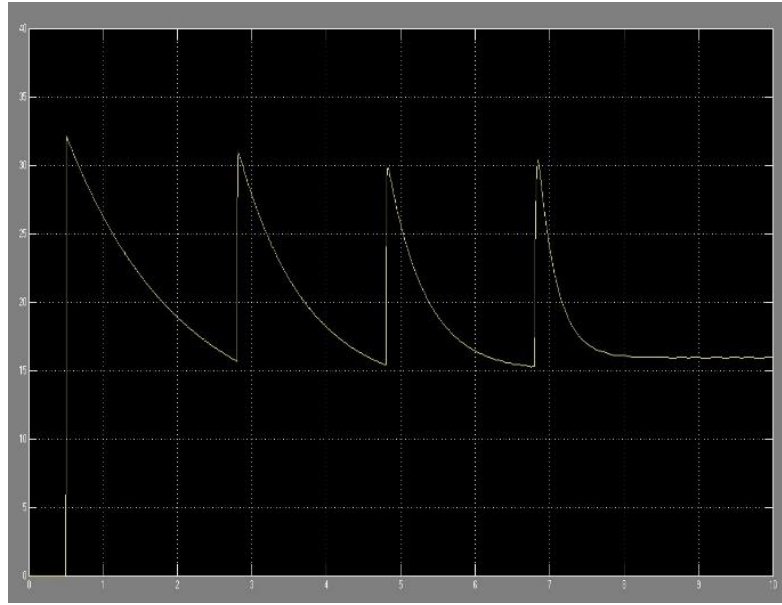

Fig (5.4): armature Current Characteristic

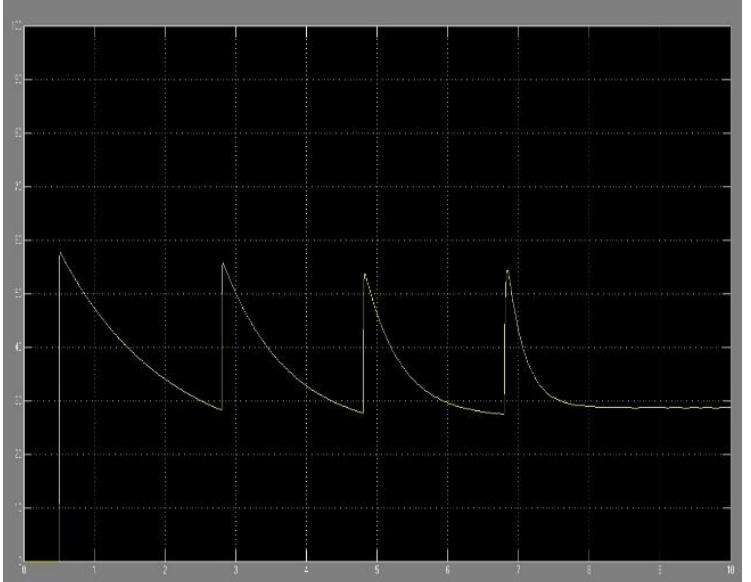

Fig (5.4): electrical torque Characteristic 
International Journal of Innovative Research in

Electrical, Electronics, Instrumentation and Control Engineering

Vol. 9, Issue 1, January 2021

DOI 10.17148/IJIREEICE.2021.9106

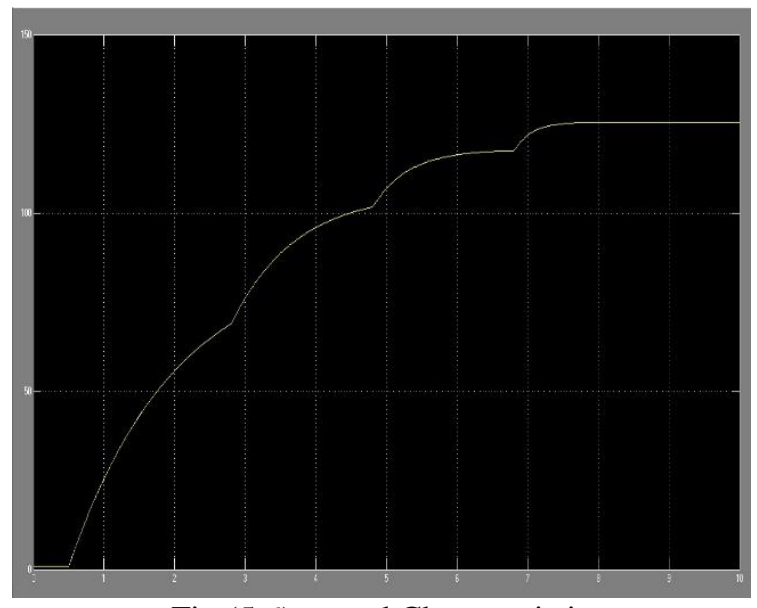

Fig (5.6): speed Characteristic

\section{DISCUSSION}

The above Figures show the starting characteristic of the DC shunt motor, as can be seen from them the armature current $\mathrm{i}_{\mathrm{a}}$, electromagnetic torque $\mathrm{T}_{\mathrm{e}}$ and the rotor speed $\mathrm{w}_{\mathrm{r}}$ are plotted verses time before to connect starter resistance and after connect starter resistance. From fig (4.1) shows that the armature current increase gradually (exponentially) from zero to 324 and then arrived to the steady state value (more than 10 time of the rated current ).from figure (4.2) the electrical torque increase gradually and then arrivedto the highest value. From figure (4.3) the speed increase from zero then arrived to the steady state value. figure (4.4) show when the contacts are open so the armature current is jumping to maximum value (32.4Amp) has already determined from the designer, hence the velocity increase from zero to high rate and follow that more generate of back emf.so the maximum value of the starting current decrease to minimum value at step one (17.526 amp).and this process repeat itself for the rest of two step until the armature current reaches the rated value at $16.2 \mathrm{amp}$. One resistor is moved and current shoots back. Three peaks show that three resistances are moved and since of each peak are same.

Fig (4.5) represent the electrical torque which proportion to value of armature current $\left(\mathrm{T}_{\mathrm{e}} \propto \mathrm{i}_{\mathrm{a}}\right)$. It rises from starting value (zeroN. m) gradually, and this process is repeated up to reach maximum value. Regarding to fig (4.4), the speed of DC shunt motor increase when the value of back emf increase. this it's obviously in this figure,the speed at initial start operation is 0 r.p.m, then start increase graduly in step (1) and becomer 65 r.p.m after that increase to 101.32 r.p.m at step (2). finally it's keep increasing until reachs the rated speed of motor (115.988r.p.m) at step (3).

\section{CONCLUSIONS}

The resistance connected in series with the armature winding after the short circuit of the segment is sufficient to limit the steady state armature current to the same maximum current. This process is repeated until the machine has reached its normal operating speed.

To limit the starting current, the motor must be started with inserting starter resistors. The number of segments and their values are determined from equations which describe steady state behavior.

\section{REFERENCES}

[1] STEPHEN J.CHAPMAN " Electric fundamentals " Fifth Edition, published by MC GRAW -HILL.

[2] JOHN WILEY \&SONS "Principles of Electric Machines" second addition.

[5]http://seminarprojects.com-[Accessed on June27/72015].

[3] theraja: electrical technology

[4] P.C KRAUSE " Analysis electrical machinery "2 nd edition MC/GRAW/ HILL/ Book Company ,1986

[5] C.V.JONES"THE UNIFIED THEORY OF LECTRICAL MACHINES" $1^{\text {ST }}$ EDITION BUTERWORTH \& Co. Ltd, 1967. 